\title{
Polymer precursors from catalytic reactions of natural oils $\nmid$
}

\author{
Marc R. L. Furst, ${ }^{a}$ Ronan Le Goff, ${ }^{a}$ Dorothee Quinzler, ${ }^{b}$ Stefan Mecking, ${ }^{b}$ Catherine H. Botting ${ }^{a}$ and \\ David J. Cole-Hamilton $* a$
}

\section{DOI: $10.1039 / \mathrm{c} 1 \mathrm{gc} 16094 \mathrm{j}$}

Dimethyl 1,19-nonadecanedioate is produced from the methoxycarbonylation of commercial olive, rapeseed or sunflower oils in the presence of a catalyst derived from $\left[\mathrm{Pd}_{2}(\mathrm{dba})_{3}\right]$, bis(ditertiarybutylphosphinomethyl)benzene (BDTBPMB) and methanesulphonic acid (MSA). The diester is then hydrogenated to 1,19-nonadecanediol using Ru/1,1,1-tris(diphenylphosphinemethyl)ethane (triphos). 1,19-Nonadecadienoic acid is hydrogenated to short chain oligoesters, which can themselves be hydrogenated to 1,19-nonadecanol by hydrogenation in the presence of water.

\section{Introduction}

As oil feedstocks dwindle, there will be a need to find alternative fuels and also alternative feedstocks that can be used to produce the many chemicals that enhance our lives. Polymeric materials have revolutionised our lives over the last 100 years, not only replacing scarce, expensive and sometimes toxic metals, cloths, etc, but also allowing the development of wholly new applications that were not contemplated until plastics were introduced on a large scale. ${ }^{1}$ Cellulose esters, used as thermoplastic materials, and vulcanised natural rubber ${ }^{2}$ were amongst the first man made plastics to be re-discovered, being already know in ancient Mesoamerica. ${ }^{3}$ These polymers were based on sustainable feedstocks, but they were soon superseded in importance by petroleum derived polymers. A return to new polymer feedstocks, once again based on natural feedstocks, may occur in the very long term. This applies, amongst others, to polyesters and polyamides as well as polyethylene, a small portion of which is already produced from renewable resources today. ${ }^{4}$

Polyamides and polyesters are usually derived from monomers which are functionalised in the $\alpha$ and $\omega$ positions, so one possible route to bioderived analogues would be to make such monomers from fatty acid esters, such as methyl oleate (methyl $Z$-octadec-9-enedioate). One way to do this is to use metathesis. $^{5-9}$ Self-metathesis gives the $\mathrm{C}_{18}$ diester, while cross

"EaStCHEM, School of Chemistry, University of St. Andrews, St. Andrews, Fife, KY169ST, Scotland,UK.E-mail: djc@st-and.ac.uk; Fax: +44 1334 463808; Tel: +441334 463805

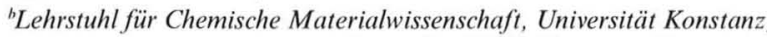
Fachbereich Chemie, Universitätsstr. 10, 78457, Konstanz, Germany. E-mail: stefan.mecking@uni-konstanz.de; Fax: +39 7531 885152; Tel: +397531882593

† Electronic supplementary information (ESI) available: Spectra of compounds (1), (2) and (3). See DOI: 10.1039/clgcl6094j metathesis with dimethyl maleate, methyl propenoate or acrylonitrile gives $\mathrm{C}_{11}$ difunctionalised products. However, in all of these reactions only half the $\mathrm{C}$ atoms from methyl oleate end up in the desired diesters, the remainder giving hydrocarbons (selfmetathesis) or monofunctionalised products (cross-metathesis). An alternative is to use a reaction in which the double bond in an unsaturated ester, such as methyl oleate is isomerised to the thermodynamically least favoured terminal position in the hydrocarbon chain, where it is trapped by a tandem reaction. Attempts to use hydroformylation as the trapping reaction have only been partially successful with low $\omega$ selectivity, ${ }^{10}$ but we have recently reported that, using methoxycarbonylation as the trapping reaction, very high selectivity $(>95 \%)$ towards dimethyl 1,19-nonadecanedioate can be obtained. ${ }^{11}$

Two of us have recently used this methoxycarbonylation reaction as part of a route to aliphatic polyesters with melting and crystallization temperatures in the range of typical thermoplastics starting from the nature-derived ester, methyl oleate. ${ }^{12,13}$ This process involves the methoxycarbonylation of methyl oleate to give dimethyl 1,19-nonadecanedioate ${ }^{11} 1$ with very high selectivity and isolated yields of over $90 \%$. The key to this remarkable reaction, which involves isomerisation of the double bond backwards and forwards along the chain, but its only being trapped by carbonylation when it is in the thermodynamically least favoured $\omega$-position relative to the ester group, is the use of a palladium based catalyst modified by the ligand bis(ditertiarybutylphosphinomethyl)benzene (BDTBPMB) 5 (Fig. 1). ${ }^{11,14,15}$
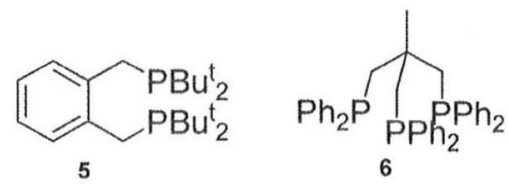

Fig. 1 Ligands used in these studies: BDTBPMB 5 and triphos 6. 
Dimethyl 1,19-nonadecanedioate 1 was reduced to 1,19 nonadecanediol 2 using $\mathrm{LiAlH}_{4}$ or by catalytic hydrogenation. Condensation of the diester with the diol gave the polyester with ester groups separated by 17 carbon atoms on the carboxylic acid side and 19 carbon atoms on the alcohol derived side. ${ }^{12,13}$ Similar chemistry was carried out starting from the unsaturated $\mathrm{C}_{23}$ ester, methyl erucate

In this paper, we report our attempts to render the syntheses of these monomers even more biocompatible. In particular, we have developed the synthesis of dimethyl 1,19-nonadecanediaote 1 directly from biological feedstocks such as olive, rapeseed and sunflower oils, so as to remove the need for extraction and purification of methyl oleate. We also report catalytic hydrogenation of the diester to 1,19-nonadecanediol 2 as a cleaner alternative to $\mathrm{LiAlH}_{4}$ reduction. Finally we report the synthesis of oligomers of 19-hydroxynonadecanoate 4 by partial hydrogenation of 1,19-nonadecanedioic acid. These reactions are outlined in Scheme 1.

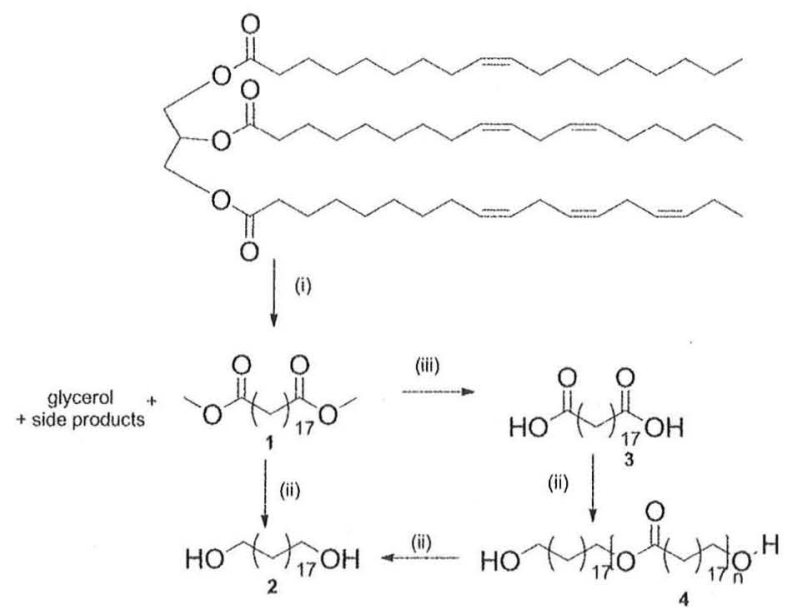

Scheme 1 (i) Formation of dimethyl 1,19-nonadecanedioate 1 by methoxycarbonylation of natural oils catalysed by $\mathrm{Pd} / \mathrm{H}^{+} / \mathrm{BDTPMB}$ 5; (ii) hydrogenation using Ru/triphos 6; (iii) hydrolysis. For conditions see the experimental and Table 2.

During the course of this work a preliminary communication has been published ${ }^{16}$ on using the same system for the catalytic carbonylation of high oleic acid sunflower oil directly to dimethyl 1,19-nonadecanedioate. We show that it is not necessary to use high oleate oils to obtain pure materials, but much cheaper vegetable oils can be used. The same communication ${ }^{16}$ also briefly describes the hydrogenation of the diester to the diol using a catalyst devised by Milstein and co-workers. ${ }^{17}$

\section{Experimental}

All reactions were performed using standard Schlenk line and glovebox techniques. Solvents were degassed with nitrogen. ${ }^{1} \mathrm{H}$ and ${ }^{13} \mathrm{C}$ nuclear magnetic resonance (NMR) spectra were recorded at $298 \mathrm{~K}$ on a Bruker $300 \mathrm{MHz}$ or $400 \mathrm{MHz}$ spectrometer for ${ }^{1} \mathrm{H}-\mathrm{NMR}$ and $75 \mathrm{MHz}$ or $100 \mathrm{MHz}$ for ${ }^{13} \mathrm{C}-\mathrm{NMR}$, using the residual solvent peak to reference the spectra to tetramethylsilane at $\delta 0 \mathrm{ppm}$. IR spectra were recorded on a Perkin Elmer Spectrum GX FT-IR spectrometer using $\mathrm{KBr}$ discs. Matrix as- sisted laser desorption time of flight mass spectrometry. MALDI MS was acquired using a 4800 MALDI-TOF/TOF Analyser (ABSciex, Foster City, CA) equipped with a Nd:YAG $355 \mathrm{~nm}$ laser and calibrated using a mixture of peptides. The sample $(0.5 \mu \mathrm{L})$, dissolved in the appropriate solvent, was applied to the MALDI target along with $\alpha$-cyano-4-hydroxycinnamic acid matrix $\left(0.5 \mu \mathrm{L}, 10 \mathrm{mg} \mathrm{mL}^{-1}\right.$ in $50: 50$ acetonitrile: $0.1 \%$ aq. TFA) and allowed to dry. The spot was analysed in positive MS mode over the appropriate mass range, by averaging 1000 laser spots. Elemental analyses were performed by the University of St Andrews Microanalytical Service. $\left[\mathrm{Pd}_{2}(\mathrm{dba})_{3}\right]$, [Ru(acac) $\left.)_{3}\right]$, 1,1,1-tris-(diphenylphosphinemethyl)ethane, zinc (Sigma Aldrich), bis(ditertiarybutyl-phosphinomethyl)benzene (Lucite International), and methanesulfonic acid (Alfa Aesar) were used as supplied. Natural oils were obtained from a local supermarket and used as supplied. They were analysed for their different carboxylic acid contents by a literature method. ${ }^{18}$

\section{Dimethyl 1,19-nonadecanedioate}

In a glovebox, $\left[\mathrm{Pd}_{2}(\mathrm{dba})_{3}\right] \quad(549 \mathrm{mg}, \quad 0.6 \mathrm{mmol})$ and bis(ditertiarybutylphosphinomethyl)benzene ( $2367 \mathrm{mg}, 6 \mathrm{mmol}$ ) were introduced into a steel autoclave and sealed. Degassed methanol $(30 \mathrm{~mL})$, natural oil $(10 \mathrm{~mL})$ and methanesulfonic acid $(0.78 \mathrm{~mL}, 12 \mathrm{mmol})$ were added to the autoclave by cannula. The autoclave was purged with $\mathrm{CO}$ and the $\mathrm{CO}$ pressure was set to $30 \mathrm{bar}$. The autoclave was heated to $80{ }^{\circ} \mathrm{C}$ for $22 \mathrm{~h}$. After cooling, venting and opening, the yellow powder was dissolved by adding dichloromethane $(20 \mathrm{~mL})$ and the yellow solution was filtered through a plug of cotton wool. The solvent was removed on a rotary evaporator until a white precipitate appeared. Cold methanol $\left(0{ }^{\circ} \mathrm{C}\right)$ was added and the mixture was stirred in an ice bath for $20 \mathrm{~min}$ before filtration. The remaining deep orange solvent was again evaporated on a rotary evaporator until a precipitate appeared, which was cooled in an ice bath for 20 $\mathrm{min}$, and filtered. The desired diester was obtained as a white powder in different isolated yields, depending on the starting natural oil; olive oil: $6.93 \mathrm{~g}(74.7 \%)$; sunflower oil: $3.36 \mathrm{~g}(36.8 \%)$; rapeseed oil: $6.44 \mathrm{~g}(69.3 \%)$. Yields are based on the amount of unsaturated esters contained in the oil. Elemental analysis: found $\mathrm{C} 71.10 \%, \mathrm{H} 11.21 \% ; \mathrm{C}_{21} \mathrm{H}_{40} \mathrm{O}_{4}$ requires $\mathrm{C} 70.74 \%, \mathrm{H}$ $11.31 \%$. 'H-NMR (400 MHz; $\left.\mathrm{CDCl}_{3}\right): \delta 3.66\left(\mathrm{~s}, 6 \mathrm{H},-\mathrm{O}-\mathrm{CH}_{3}\right)$, 2.29 (t, $J=7.6 \mathrm{~Hz}, 4 \mathrm{H},-\mathrm{CH}_{2}-\mathrm{CO}-\mathrm{O}-\mathrm{CH}_{3}$ ), 1.61 (quintet, $J=$ $\left.7.3 \mathrm{~Hz}, 4 \mathrm{H},-\mathrm{CH}_{2}-\mathrm{CH}_{2}-\mathrm{CO}-\mathrm{O}-\mathrm{CH}_{3}\right), 1.24$ (s, 26H, alkyl chain). ${ }^{13} \mathrm{C}-\mathrm{NMR}\left(100 \mathrm{MHz} ; \mathrm{CDCl}_{3}\right): \delta 174.49$ (s, $C_{\text {carbonyl }}$ ), 51.58 (s, $C_{\text {methoxy }}$ ), $34.26\left(\mathrm{~s},-\mathrm{CH}_{2}-\mathrm{C}_{\text {carbonyl }}\right), 29.81(\mathrm{~s}), 29.78(\mathrm{~s}), 29.74$ (s), 29.60 (s), 29.40 (s), 29.30 (s), 25.11 (s, $-\mathrm{CH}_{2}-\mathrm{CH}_{2}-\mathrm{C}_{\text {carbonyl) }}$ ) These data are consistent with those described in the literature. ${ }^{12}$

\section{1,19-Nonadecanedioic acid ${ }^{13}$}

Dimethyl 1,19-nonadecanedioate (400 mg, $1.12 \mathrm{mmol})$ was introduced into a round bottom flask. Dioxane $(30 \mathrm{~mL})$, distilled water $(20 \mathrm{~mL})$ and hydrochloric acid $(36 \%$ in water, 1 drop, $10 \mathrm{mg}, 0.28 \mathrm{mmol}$ ) were added and the mixture was left to reflux overnight. After cooling, the solvent was removed on a rotary evaporator. Distilled water $(100 \mathrm{~mL})$ was added and the heterogeneous mixture stirred fast before being filtered through a Büchner funnel. The white solid was washed with water $(50 \mathrm{~mL})$ and dried under vacuum. The desired diacid was obtained as 
a white powder $(230 \mathrm{mg}, 62 \%)$. Elemental analysis: found $\mathrm{C}$ $69.62 \%, \mathrm{H} 10.91 \% ; \mathrm{C}_{19} \mathrm{H}_{36} \mathrm{O}_{4}$ requires C $69.47 \%$, H $11.05 \%$. 'H-NMR (300 MHz; THF): $\delta 10.54$ (br s, $2 \mathrm{H},-\mathrm{CO}_{2} H$ ), 2.21 (t, $J=7.4 \mathrm{~Hz}, 4 \mathrm{H},-\mathrm{CH}_{2}-\mathrm{CO}_{2} \mathrm{H}$ ), 1.57 (quintet, $J=7.2 \mathrm{~Hz}$, $\left.4 \mathrm{H},-\mathrm{CH}_{2}-\mathrm{CH}_{2}-\mathrm{CO}_{2} \mathrm{H}\right), 1.30$ (s, 30H, alkyl chain). ${ }^{13} \mathrm{C}-\mathrm{NMR}$ (75 MHz; THF): $\delta 174.41\left(\mathrm{~s},-\mathrm{CO}_{2} \mathrm{H}\right), 34.23\left(\mathrm{~s},-\mathrm{CH}_{2}-\mathrm{CO}_{2} \mathrm{H}\right)$, 30.62-30.12 ( $\mathrm{m}$, alkyl chain).

\section{1,19-Nonadecanediol}

First method. $\left[\mathrm{Ru}(\mathrm{acac})_{3}\right](4.5 \mathrm{mg}, 0.011 \mathrm{mmol}), 1,1,1$-tris(diphenylphosphinemethyl)ethane (14 mg, $0.022 \mathrm{mmol})$ and dimethyl nonadecanedioate $(393 \mathrm{mg}, 1.103 \mathrm{mmol})$ were introduced into an autoclave and sealed. The autoclave was purged three times with nitrogen. Dioxane $(10 \mathrm{~mL})$ and water $(1 \mathrm{~mL})$ were introduced via cannula. The autoclave was purged with $\mathrm{H}_{2}$ and the $\mathrm{H}_{2}$ pressure was set to 40 bar before heating to $220^{\circ} \mathrm{C}$ for $16 \mathrm{~h}$. After cooling, depressurising and opening, the crude mixture was transferred to a round bottom flask $(50 \mathrm{~mL})$. The solvent was removed on a rotary evaporator. Dichloromethane $(10 \mathrm{~mL})$ was added and the yellow solution containing white crystals was stirred for $20 \mathrm{~min}$ before filtration. The desired diol was obtained as a white powder $(265 \mathrm{mg}, 80 \%)$. Elemental analysis: found $\mathrm{C} 75.93 \%, \mathrm{H} 13.36 \% ; \mathrm{C}_{19} \mathrm{H}_{40} \mathrm{O}_{2}$ requires $\mathrm{C} 75.94$, H 13.42\%. 'H-NMR (300 MHz; THF): $\delta 3.45$ (t, $J=6.4 \mathrm{~Hz}$, $4 \mathrm{H},-\mathrm{CH}_{2}-\mathrm{OH}$ ), 1.45 (quintet, $J=6.1 \mathrm{~Hz}, 4 \mathrm{H},-\mathrm{CH}_{2}-\mathrm{CH}_{2}-$ $\mathrm{OH}), 1.28$ (s, 30H, alkyl chain). ${ }^{13} \mathrm{C}-\mathrm{NMR}$ (75 MHz; THF): $\delta$ 62.53 (s, $-\mathrm{CH}_{2}-\mathrm{OH}$ ), 34.11 (s, $\left.-\mathrm{CH}_{2}-\mathrm{CH}_{2}-\mathrm{OH}\right), 30.68$ (s), 30.62 (s), 30.55 (s), 26.93 (s, $-\mathrm{CH}_{2}-\mathrm{CH}_{2}-\mathrm{CH}_{2}-\mathrm{OH}$ ). These data are consistent with those described in the literature. ${ }^{12}$

Second method. $\left[\mathrm{Ru}(\mathrm{acac})_{3}\right](4.5 \mathrm{mg}, 0.011 \mathrm{mmol}), 1,1,1-$ tris-(diphenylphosphinemethyl)ethane (14 mg, $0.022 \mathrm{mmol}$ ), dimethyl nonadecanedioate $(393 \mathrm{mg}, 1.103 \mathrm{mmol}$ ) and zinc powder $(8.6 \mathrm{mg}, 0.132 \mathrm{mmol}$ ), were introduced into an autoclave and sealed. The autoclave was purged three times with nitrogen. Methanol $(10 \mathrm{~mL})$ was introduced via cannula. The autoclave was purged with $\mathrm{H}_{2}$ and the $\mathrm{H}_{2}$ pressure was set to 70 bar. The autoclave was heated to $140{ }^{\circ} \mathrm{C}$ for $16 \mathrm{~h}$. After cooling, venting and opening, dichloromethane $(10 \mathrm{~mL})$ was added and the mixture transferred to a round bottom flask $(50 \mathrm{~mL})$. The solvent was removed on a rotary evaporator. Dichloromethane $(10 \mathrm{~mL})$ was added and the yellow solution containing white crystals was stirred for $20 \mathrm{~min}$. The two phase mixture was allowed to settle for $20 \mathrm{~min}$ (the product stays in the upper phase, the metallic zinc stays at the bottom). The upper phase was decanted and filtered. The desired diol was obtained as a white powder ( $270 \mathrm{mg}, 81 \%)$. Elemental analysis: found C 76.03 ,
$\mathrm{H} 13.17 \% ; \mathrm{C}_{19} \mathrm{H}_{40} \mathrm{O}_{2}$ requires C 75.94, $\mathrm{H} 13.42 \% .{ }^{1} \mathrm{H}-\mathrm{NMR}(400$ MHz; THF): $\delta 3.46\left(\mathrm{t}, J=6.5 \mathrm{~Hz}, 4 \mathrm{H},-\mathrm{CH}_{2}-\mathrm{OH}\right), 1.47$ (quintet, $\left.J=6.7 \mathrm{~Hz}, 4 \mathrm{H},-\mathrm{CH}_{2}-\mathrm{CH}_{2}-\mathrm{OH}\right), 1.30(\mathrm{~s}, 30 \mathrm{H}$, alkyl chain). ${ }^{13} \mathrm{C}-\mathrm{NMR}$ (100 MHz; THF): $\delta 62.54$ (s, $-\mathrm{CH}_{2}-\mathrm{OH}$ ), 34.11 (s, $-\mathrm{CH}_{2}-\mathrm{CH}_{2}-\mathrm{OH}$ ), 30.69, (s) 30.63 (s), 30.55 (s), 26.93 (s, $-\mathrm{CH}_{2}-$ $\mathrm{CH}_{2}-\mathrm{CH}_{2}-\mathrm{OH}$ ).

Oligoesters were prepared using the first method described above for the diol, starting from nonadecanedioic acid, in anhydrous dioxane. The oligomers were obtained as white solids. Elemental analysis: found $\mathrm{C} 75.83 \%, \mathrm{H} 11.64 \% ; \mathrm{C}_{57} \mathrm{H}_{112} \mathrm{O}_{6}$ (i.e. oligomers with 3 units terminated by $-\mathrm{OH}$ groups) requires $\mathrm{C}$ $76.62 \%$, H $12.63 \%$. Typical NMR data: 'H-NMR (400 MHz; $\left.\mathrm{CDCl}_{3}\right): \delta 4.05\left(\mathrm{t}, J=6.8 \mathrm{~Hz}, 1 \mathrm{H},-\mathrm{CO}-\mathrm{O}-\mathrm{CH}_{2}-\right), 3.64(\mathrm{t}, J=$ $\left.6.6 \mathrm{~Hz}, 1 \mathrm{H},-\mathrm{CH}_{2}-\mathrm{OH}\right), 2.28\left(\mathrm{t}, J=7.6 \mathrm{~Hz}, 1 \mathrm{H},-\mathrm{CH}_{2}-\mathrm{CO}-\mathrm{O}-\right.$ $\left.\mathrm{CH}_{2}-\right), 1.64-1.53(\mathrm{~m}, 3 \mathrm{H}), 1.25$ (s, 22H, alkyl chain), 0.88 (t, $J=$ $6.9 \mathrm{~Hz}$, saturated end group). ${ }^{13} \mathrm{C}-\mathrm{NMR}\left(100 \mathrm{MHz} ; \mathrm{CDCl}_{3}\right): \delta$ 64.56 (s, $-\mathrm{CH}_{2}-\mathrm{CO}-\mathrm{O}-\mathrm{CH}_{2}-$ ), 63.26 (s, $\left.-\mathrm{CH}_{2}-\mathrm{OH}\right), 34.58$ (s), 32.98 (s), 29.83-28.82 (m, alkyl chain), 26.10 (s), 25.90 (s), 25.19 (s). IR: $3450 \mathrm{~cm}^{-1}\left(v_{\mathrm{OH}}\right), 2918 \mathrm{~cm}^{-1}$ and $2850 \mathrm{~cm}^{-1}\left(v_{\mathrm{CH}}\right), 1735$ $\mathrm{cm}^{-1}\left(v_{\mathrm{C}=0}\right), 1630 \mathrm{~cm}^{-1}, 1470 \mathrm{~cm}^{-1}\left(\mathrm{CH}_{2}\right), 1180 \mathrm{~cm}^{-1}, 1060 \mathrm{~cm}^{-1}$, $720 \mathrm{~cm}^{-1}\left(\mathrm{CH}_{2}\right)$.

\section{Results and discussion}

\section{1,19-Nonadecandioate from natural oils}

Our previous studies on the hydrogenation of unsaturated $\mathrm{C}_{18}$ esters ${ }^{11}$ led us to investigate whether 1 could be obtained from oils that contain substantial amounts of $\mathrm{C}_{18}$ fatty acid esters with different amounts of unsaturation, reasoning that methanolysis of the triglyceride esters and methoxycarbonylation should occur in tandem under the reaction conditions. The oils were obtained from a local supermarket and were chosen for their different proportions of oleic, linoleic and linolenic acid esters (Table 1).

Using a method very similar to that described previously ${ }^{12,13}$ for the methoxycarbonylation of methyl oleate, a one-pot synthesis of 1 from natural oils has been successfully achieved, affording the desired product as an analytically pure snowy white powder, with NMR spectra as reported earlier. ${ }^{12,13}$ The yields obtained from $10 \mathrm{~mL}$ of oil, as well as the $\%$ conversion of $\mathrm{C}_{18}$ chains are shown in Table 1 . The yield reduces in the order olive oil $>$ rapeseed oil $>$ sunflower oil, reflecting the differing amounts of triglyceride oleate present in the starting oils. This one-pot process represents a significant enhancement in the viability of production of $\mathbf{1}$ since it starts from standard quality natural oils with no extra purification and avoids the multiple reaction and purification steps usually required for

Table 1 Composition of natural oils ${ }^{a}$ and the yields of dimethyl 1,19-nonadecanedioate , $\mathbf{1}$, obtained

\begin{tabular}{lllll}
\hline & Methyl oleate (Aldrich) & Olive (supermarket) & Rapeseed (supermarket) & Sunflower (supermarket) \\
\hline Oleate/\% & $>90$ & 73 & 64 & 38 \\
Linoleate $/ \%$ & & 2 & 19 & 50 \\
Linolenate $/ \%$ & 3 & 10 & 2 \\
Diester/g from $10 \mathrm{~mL}$ of oil & 9.0 & 6.9 & 6.4 & 3.4 \\
Yield (from oleate) $/ \%$ & & $74.7(102.3)$ & $69.3(108.3)$ & $36.8(96.8)$
\end{tabular}

a Unsaturated $\mathrm{C}_{18}$ fraction only, the remaining fatty acid residues are from different chain lengths (mainly $\mathrm{C}_{16}$ and $\mathrm{C}_{23}$ ) and from stearic (saturated $\mathrm{C}_{18}$ ) acids. ${ }^{b}$ Yields are calculated assuming the molecular mass of the starting material is equivalent to glycerol trioleate $(885.43 \mathrm{amu})$. 
high purity methyl oleate as a feedstock. The yields suggest that the isolated diester arises mainly from the oleate chains in the oils. This suggestion is supported by GC analysis of the crude reaction products. Due to the multitude of compounds present and the often similar or identical masses and similar fragmentation patterns, full assignments from GC-MS are problematic. However, the main impurities are glycerol and methyl esters of saturated fatty acids of different chain lengths which are present as glycerol esters in the feed oil. Peak $\mathrm{j}$ in the GC-MS traces shown in the ESI†, which is much more intense in the products from sunflower oil than from olive oil, with a slightly shorter retention time than that for dimethyl 1,19nonadecanedioate $\mathbf{1}$ (peak k) and a parent ion at $354 \mathrm{amu}$, can be assigned tentatively to (isomeric) dimethyl nonadecenedioate. This is relevant in view of the significant linoleate content of many feedstocks (Table 1), and shows that this material is also carbonylated to linear products ( $c f$. ESI $\dagger$ ). Further studies on the methoxycarbonylation of methyl linoleate are currently in progress and will be reported separately. ${ }^{19}$ Full GC-MS traces with mass spectra are shown in the ESI†.

\section{Hydrogenation of dimethyl 1,19-nonadecanedioate}

The hydrogenation of esters and carboxylic acids, which are amongst the more difficult hydrogenations to have been reported, ${ }^{20}$ has traditionally been carried out using copper chromite at high temperatures and pressures. The first homogeneous catalysts for this reaction, ruthenium complexes of $1,1,1$ tris-(diphenylphosphinemethyl)ethane (triphos, 6, Fig. 1) were described by Elsevier and co-workers. ${ }^{21-23}$ Initially, the reactions only worked with activated acids such as oxalic acid, which could be hydrogenated to 1,2-ethanediol with high selectivity. ${ }^{21}$ Further developments by the same group ${ }^{22,23}$ but also by workers at Davy Process Technology ${ }^{24,25}$ extended the substrate scope to cover other acids including simple aliphatic carboxylic acids. High activities towards primary alcohols were achieved by adding water ( $10 \%$ volume) and working at high temperature $\left(220^{\circ} \mathrm{C}\right){ }^{24,25}$ It is thought that the high temperatures required to obtain good rates lead to the decarbonylation of an aldehyde or other reaction intermediate to give $\left[\mathrm{RuH}_{2}(\mathrm{CO})\right.$ (triphos)] 7 , which is catalytically inactive (Top half of Scheme 2) ${ }^{24}$ Ruthenium carbonyl complexes are sometimes synthesised by

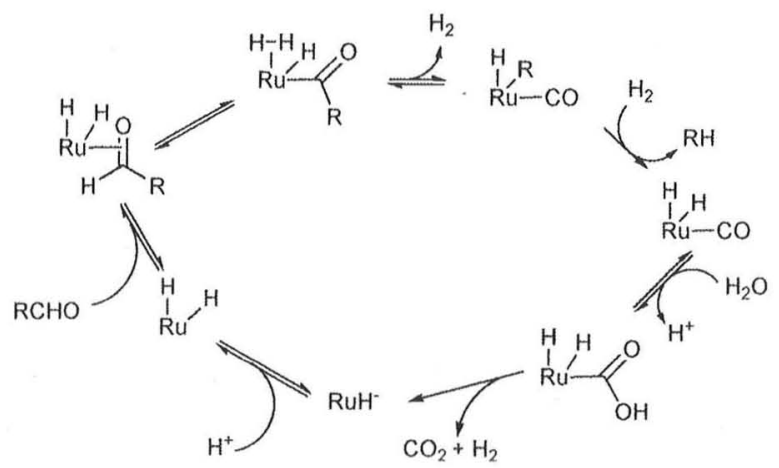

Scheme 2 Proposed poisoning of the catalyst 7 by decarbonylation of an aldehyde intermediate and the regeneration of the catalyst by water-gas shift type reactions. Triphos, which occupies the other three coordination sites, has been omitted for clarity. decarbonylation of alcohols and the mechanism is quite well understood. ${ }^{26}$ In addition, we have isolated $\left[\mathrm{RuH}_{2}(\mathrm{CO})\right.$ (triphos)] from a reaction of $\left[\mathrm{Ru}(\mathrm{acac})_{3}\right]$, and triphos in methanol under hydrogen, ${ }^{27}$ and others have isolated the same complex from the hydrogenation of levulinic acid under similar conditions. ${ }^{28}$ Water is then required to return the catalyst into an active form by water-gas shift type chemistry (bottom half of Scheme 2). ${ }^{24}$ An alternative method for hydrogenating simple esters using 7 as the catalyst involves carrying out the hydrogenation in methanol in the presence of zinc, where good activities could be obtained at $140{ }^{\circ} \mathrm{C} .{ }^{21}$ Original suggestions that triphos is active because it coordinates in a facial manner have been challenged by the discovery of several other catalysts, which do not contain facially coordinating ligands but which are active for ester and acid hydrogenation..$^{17,29,30}$ Indeed some of us have recently reported that nonadecane-1,19-diol as well as tricosane-1,23-diol can be formed in high yields and with more than $99 \%$ purity, using dichlorobis[2-(diphenylphosphino)ethylamine]ruthenium as the catalyst. ${ }^{13}$

Leitner and co-workers have reported the successful hydrogenation of levulinic acid using the same catalyst under similar conditions (added water, $220{ }^{\circ} \mathrm{C}, 40$ bar) and have shown that the acid is more successfully reduced than the methyl ester. ${ }^{28}$ In some of their reactions, they added $\left[\mathrm{NH}_{4}\right] \mathrm{PF}_{6}$ which will undoubtedly react with water to give $\mathrm{HF}$ and $\left[\mathrm{O}_{2} \mathrm{PF}_{2}\right]^{-31}$ This led us to investigate whether addition of acid might enhance our hydrogenation reactions, which had shown variable reproducibility depending upon the batch of triphos employed. Under the high temperature conditions $\left(220^{\circ} \mathrm{C}\right.$ in dioxane containing $10 \%$ water), in the presence of catalytic amounts of methanesulfonic acid (MSA), 2 was not produced as expected (Table 2, entry 1). Furthermore, the reaction in the presence of MSA could not be successfully carried out without any added water (Table 2, entry 2). Using lower temperature conditions (dry methanol, zinc powder $(12 \% \mathrm{~mol}), 140{ }^{\circ} \mathrm{C}$ ) and addition of MSA, allows the reproducible production of $\mathbf{2}$ in high yield (Table 2, entry 3). Full conversion to diol is also observed under these conditions if zinc is omitted (Table 2, entry 4).

Afterwards, we attempted to carry out the same reactions in the absence of MSA. Full conversion was obtained at $220^{\circ} \mathrm{C}$ in dioxane containing $50 \%$ water (Table 2, entry 5 ). As suggested in Scheme 2, the role of water is to regenerate the poisoned catalyst into an active species by a water-gas shift type reaction. In order

Table 2 Production of 2 by hydrogenation of 1 catalysed by Ru complexes of $\mathbf{6}^{a}$

\begin{tabular}{llllll}
\hline Entry & Solvent & Water/\% & $\begin{array}{l}\text { MSA/ } \\
\text { mmol }\end{array}$ & T/ ${ }^{\circ} \mathrm{C}$ & $\begin{array}{l}\text { Yield/\% } \\
\text { GC-(isolated) }\end{array}$ \\
\hline 1 & Dioxane & 10 & 0.111 & 220 & $<1$ \\
2 & Dioxane $^{b}$ & 0 & 0.111 & 220 & $<1$ \\
3 & Methanol $^{b}$ & 0 & 0.111 & 140 & $>99-(81)$ \\
4 & Methanol $^{c}$ & 0 & 0.111 & 140 & $>99-(63)$ \\
5 & Dioxane $^{2}$ & 50 & 0 & 220 & $>99-(76)$ \\
6 & Dioxane & 10 & 0 & 220 & $>99-(73)$ \\
7 & Dioxane & 0.6 & 0 & 220 & 18 \\
8 & Dioxane & 0 & 0 & 220 & 13
\end{tabular}

${ }^{a}\left[\mathrm{Ru}(\mathrm{acac})_{3}\right](4.5 \mathrm{mg}, 0.011 \mathrm{mmol}) ; 6(14 \mathrm{mg}, 0.022 \mathrm{mmol}), 1(393 \mathrm{mg}$, $1.103 \mathrm{mmol}), \mathrm{H}_{2}$ (40 bar), dioxane/water $(10 \mathrm{~mL}) ;{ }^{b} \mathrm{Zn}(8.6 \mathrm{mg}$, $0.132 \mathrm{mmol}) ;{ }^{c} \mathrm{No} \mathrm{Zn}$ 
to investigate more about the role of water during the reaction, the amount of water was successively decreased from $5 \mathrm{~mL}$ to $1 \mathrm{~mL}, 0.06 \mathrm{~mL}$ and $0 \mathrm{~mL}$. We saw full conversion to diol when a large excess of water in dioxane $(50 \%$ to $10 \%$, Table 2 , entries 5 and 6) was employed, but the conversion of 1 to 2 decreased dramatically if only a small amount $(0.6 \%$, Table 2 , entry 7$)$ of water was added or if it was omitted entirely (Table 2, entry 8). The large amounts of water required for hydrogenation reactions in dioxane may suggest that the water is not only required for catalyst regeneration as in Scheme 2, but also for ester hydrolysis and that the acid formed may be the active species being hydrogenated. To test this hypothesis, we prepared the diacid $\mathbf{3}$ by an acid catalysed hydrolysis of species $\mathbf{1}$ and hydrogenated it in the absence of both water and MSA (conditions were the same as for Table 1, entry 8). Surprisingly, we observed the production of a white solid, for which NMR spectroscopy, MALDI-TOF mass spectrometry (MTMS) and IR analyses suggest that partial hydrogenation to 19-hydroxynonadecanoic acid occurs, followed by a condensation esterification to give oligoesters 4 (for spectra see ESI $\dagger$ ). The IR spectrum shows that hydroxy $\left(v_{\mathrm{OH}}=3450 \mathrm{~cm}^{-1}\right)$ and ester carbonyl groups $\left(v_{\mathrm{CO}}=\right.$ $1735 \mathrm{~cm}^{-1}$ ) are present. Hydroxy end groups are also observed in the 'H-NMR spectrum, which shows that the average chain length of the isolated polymer is three units. The crude product also contains diol. The MTMS suggests that the oligomers are mostly short chains (up to four monomer units).

Detailed analysis of the MTMS shows that each chain length of oligomer can have several different end groups. The peaks corresponding to oligomers of chain lengths with four monomer units are shown in Fig. 2. Well defined clusters of peaks are observed and are separated by 14 mass units. The main signals arise from oligoesters in which the terminal units are diol $(2 \times$ $\mathrm{OH})$ hydroxyacid $\left(\mathrm{OH}, \mathrm{CO}_{2} \mathrm{H}\right)$, or diacid $\left(2 \times \mathrm{CO}_{2} \mathrm{H}\right)$.

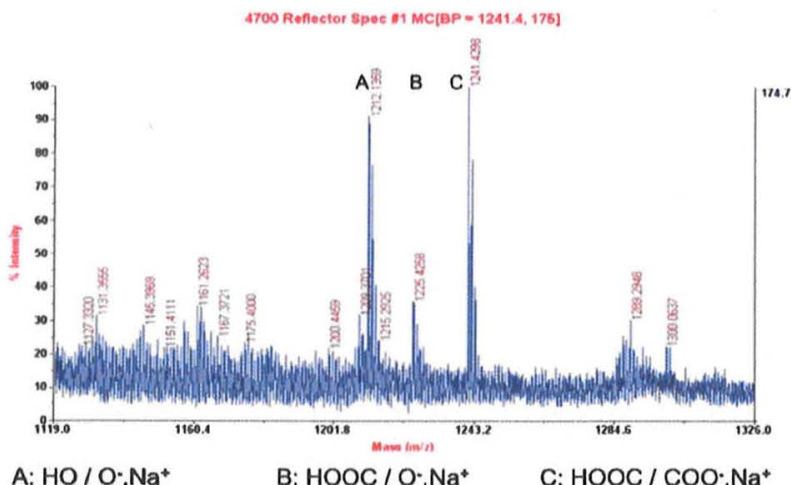

Fig. 2 MTMS peaks and proposed assignments of a tetramer from the hydrogenation of nonadecanedioic acid.

Since hydrogenation of the 1,19-nonadecanedioic acid produced an oligomeric material in the absence of water, we considered the possibility that a further role of water might be to hydrolyse the oligomers formed, allowing their successful hydrogenation.

While the hydrogenation of dimethyl 1,19-nonadecanedioate 1 led reproducibly to the diol when using most batches of triphos, an earlier batch, which contained impurities, led to oligoesters with a variety of end groups. In order to see if these could be intermediates in the formation of the diol, we took one of the samples of oligoester (see ESI† for its structure) and hydrogenated it in dioxane/water $(1: 1)$ with a catalyst derived from pure triphos. Full conversion to 2 was obtained, confirming our previous hypothesis that water can aid in depolymerisation reactions.

Three approaches to the hydrogenation of dimethyl 1,19nonadecanedioate 1 have now been described using three different catalytic systems. The catalysts are shown in Fig. 3. Each of them has some disadvantages. Catalysts $7^{13}$ and $8^{16}$ both require fairly sophisticated ligands, and 7 requires a large amount of base ( $\mathrm{NaOMe})$. However, they both operate under relatively mild conditions $\left(50 \mathrm{bar}, 100^{\circ} \mathrm{C}, 22 \mathrm{~h}\right.$ for 7 and $10 \mathrm{bar}$, $115^{\circ} \mathrm{C}$ for 8 ) whereas, the simpler catalyst system 9 (this work), formed in situ from readily available materials requires rather higher temperatures $\left(140-200^{\circ} \mathrm{C}\right)$.

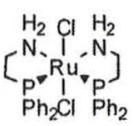

7

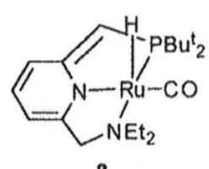

$\left.[\text { Ru(acac) })_{3}\right]$ / triphos / MSA
Fig. 3 Catalysts used for the hydrogenation of dimethyl 1,19nonadecanedioate to 1,19-nonadecanediol.

\section{Conclusions}

Dimethyl 1,19-nonadecanedioate can be conveniently prepared in high purity from the methoxycarbonylation of cheap and readily available olive, rapeseed or sunflower oils. The diester can be hydrogenated using $\mathrm{Ru} /$ triphos in the presence of water to give 1,19-nonadecanediol. 1,19-Nonadecanedoic acid can by hydrogenated in the absence of MSA and water but only to short chain oligoesters. Such oligoesters can be hydrogenated to 1,19nonadecanediol if water is added. Here, water may have three key roles: it may recycle inactive carbonyl compounds formed from the active catalyst by water-gas shift type chemistry; it may hydrolyse the starting diester to the carboxylic acid, thus generating the acid required to promote the reaction; it may assist in hydrolysing the intermediate oligoesters that might otherwise precipitate during the reaction.

\section{Notes and references}

1 N. G. McCrum, C. P. Buckley and C. B. Bucknall, Principles of polymer engineering, Oxford University Press, Oxford, 1999

2 Goodyear, Letters Patent, 1837, 240.

3 D. Hosler, S. L. Burkett and M. J. Tarkanian, Science, 1999, 284, 1988.

4 D. V. Rosato and M. V. Rosato, Plastic product material and process selection handbook, Elsevier, North Holland, 2004.

5 A. Behr, A. Westfechtel and J. P. Gomes, Chem. Eng. Technol., 2008, 31, 700 .

6 R. Duque, E. Ochsner, H. Clavier, F. Caijo, S. P. Nolan, M. Mauduit and D. J. Cole-Hamilton, Green Chem., 2011, 13, 1187.

7 X. Miao, P. H. Dixneuf, C. Fischmeister and C. Bruneau, Green Chem., 2011, 13, 2258.

8 U. Biermann, U. Bornscheuer, M. A. R. Meier, J. O. Metzger and H. J. Schaefer, Angew. Chem., Int. Ed., 2011, 50, 3854.

9 R. Malacea and P. Dixnuef, in Green Metathesis Chemistry, ed. V. Dragutuan, A. Demonceau, I. Dragutuan and E. S. Finkelstein, Springer, Dordrecht, 2008, pp. 185 
10 A. Behr, D. Obst and A. Westfechtel, Eur. J. Lipid Sci. Technol., 2005, 107, 213.

11 C. Jimenez-Rodriguez, G. R. Eastham and D. J. Cole-Hamilton, Inorg. Chem. Commun., 2005, 8, 878.

12 D. Quinzler and S. Mecking, Angew. Chem., Int. Ed., 2010, 49, 4306.

13 F. Stempfle, D. Quinzler, I. Heckler and S. Mecking, Macromolecules, $2011, \mathbf{4 4}, 4159$.

14 C. J. Rodriguez, D. F. Foster, G. R. Eastham and D. J. Cole-Hamilton, Chem. Commun., 2004, 1720.

15 A. A. Nunez-Magro, L. M. Robb, P. J. Pogorzelec, A. M. Z. Slawin, G. R. Eastham and D. J. Cole-Hamilton, Chem. Sci., 2010, 1, 723 .

16 G. Walther, J. Deutsch, A. Martin, F.-E. Baumann, D. Fridag and A. Köckritz, ChemSusChem, 2011, 4, 1052.

17 J. Zhang, G. Leitus, Y. Ben-David and D. Milstein, Angew. Chem., Int. Ed., 2006, 45, 1113 .

18 G. Knothe and J. A. Kenar, Eur. J. Lipid Sci. Technol., 2004, 106, 88.

19 F. Stempfle, P. Rösle and S. Mecking, to be published.

20 A. T. Blomquist and A. Goldstein, Org. Syn, 1963, 4, 216.

21 H. T. Teunissen and C. J. Elsevier, Chem. Commun., 1997, 667.
22 H. T. Teunissen and C. J. Elsevier, Chem. Commun., 1998, 1367.

23 M. C. van Engelen, H. T. Teunissen, J. G. de Vries and C. J. Elsevier, J. Mol. Catal. A: Chem., 2003, 206, 185.

24 S. P. Crabtree, D. V. Tyers and M. Sharif, World Pat., WO 05/051907A1, 2005

25 M. Kilner, D. V. TyersS. P. Crabtree, and M. A. Wood, World Pat., 03/09328, 2003.

26 B. N. Chaudret, D. J. Cole-Hamilton, R. S. Nohr and G. Wilkinson, J. Chem. Soc, Dalton Trans., 1977, 1546.

27 A. A. Nunez-Magro, PhD Thesis, University of St. Andrews, 2007.

28 F. M. A. Geilen, B. Engendahl, A. Harwardt, W. Marquardt, J. Klankermayer and W. Leitner, Angew. Chem., Int. Ed., 2010, 49, 5510 .

29 M. L. Clarke, M. B. Diaz-Valenzuela and A. M. Z. Slawin, Organometallics, 2007, 26, 16

30 L. A. Saudan, C. M. Saudan, C. Debieux and P. Wyss, Angew. Chem., Int. Ed., 2007, 46, 7473.

31 G. Smith, D. J. Cole-Hamilton, A. C. Gregory and N. G. Gooden, Polyhedron, 1982, 1, 97 